\title{
Modeling the Share of Cash Payments in the Economy: An Application to France*
}

\author{
Yassine Bouhdaoui and David Bounie \\ Economics and Social Sciences Department, Telecom ParisTech
}

\begin{abstract}
Modeling the demand for cash and deposits is a primary concern for central banks. Within a wide range of academic contributions, payment choice models based on transaction sizes (TS models) have been promoted. However, TS models induce strong predictions about the use of payment instruments. In particular, all equal-sized transactions are supposed to be paid with the same payment instrument. We propose a simple alternative model based on cash holding ( $\mathrm{CH}$ model) that allows equal-sized transactions to be paid for in cash or with other payment instruments. Using micro-level payment data from two representative samples of the French population in 2005 and 2011, we test how well each model replicates the observed shares of cash payments in the French economy for each size of transaction. We find that the $\mathrm{CH}$ model outperforms TS models, as it better predicts the observed shares of cash payments with notably less demanding information on individuals.
\end{abstract}

JEL Codes: E41, G2.

${ }^{*}$ We are especially indebted to Nicolas Houy and Abel Franois, who have significantly contributed to the development of the ideas contained in this research. We also thank participants of the conference entitled "The Economics of Payments III" held at the Federal Reserve Bank of Atlanta for their helpful comments as well as the anonymous referee for her/his constructive comments and detailed suggestions on an earlier draft of the paper. Author e-mails: yassine.bouhdaoui@telecom-paristech.fr, david.bounie@telecom-paristech.fr (corresponding author). 


\section{Introduction}

For several decades, monetary economists have expressed a considerable interest in modeling demand for currency and deposits. ${ }^{1}$ Within a wide range of contributions, two distinct lines of analysis have been proposed. The first one - represented by Santomero (1974, 1979), Santomero and Seater (1996), and their references - developed formal models in which demand for currency and deposits is a direct function of rates of return and fixed costs of transaction. These models have never been directly estimated, due to their complexity (Folkertsma and Hebbink 1998). The second line of analysis, promoted by Whitesell $(1989,1992)$ and Shy and Tarkka (2002), relies on more tractable models. Whitesell shows that when the transaction costs depend on the transaction size, the demand for currency and deposits may be considerably affected. ${ }^{2}$ A central implication of these models is that all equal-sized transactions are paid with the same payment instrument and each payment instrument dominates a particular domain of transaction. That is, cash is used for transaction sizes below a given threshold (small-value purchases) and alternative payment instruments are used for transaction sizes above the threshold (large-value purchases). Since these models are related to transaction sizes, we will call them "TS models."

The role of transaction sizes and transaction costs on consumer payment patterns has been studied in recent empirical papers. Boeschoten (1992), Mot and Cramer (1992), Hayashi and Klee (2003), Bounie and Franois (2006), and Klee (2008) confirmed that larger transactions are more often paid by check or payment card than by cash. Likewise, Carow and Staten (1999), Zinman (2009), and their references have confirmed the role of transaction fees on the use of payment instruments. However, to the best of our knowledge, the ability of TS models to replicate the use of payment instruments has never been tested in any of the aforementioned studies. Now, to what extent do TS models provide a good prediction of the shares of cash and other payments in an economy?

\footnotetext{
${ }^{1}$ Recent references centered on the demand for cash include, to name but a few, Alvarez and Lippi (2009) and Lippi and Secchi (2009).

${ }^{2}$ Shy and Tarkka (2002) apply their model to electronic money, and Bounie and Franois (2011) apply theirs to bill payments.
} 
The main objective of this paper is to address this question. Our purpose is to test the ability of TS models to replicate the observed shares of cash and other payments in the French economy rather than to estimate, as in previous empirical studies, the effects of the transaction size or the transaction costs on the use of payment instruments. We proceed in two steps. In the first one, we define three payment choice models. The first two are TS models and the third one is a model based on the individual's cash holding that we call the "CH model." In the second step, we measure how well these models replicate the observed shares of cash payments using data from two representative samples of the French population in 2005 and 2011. The first TS model is naive and considers a representative agent who uses cash to pay all the transactions below a fixed threshold. As expected, this model performs very poorly. The second TS model considers a representative agent with a probabilistic threshold instead of a fixed one. The probability distribution of thresholds is calculated from the payment behaviors of individuals. This latter model performs much better but is very demanding in terms of information. Finally, the third model, based on individuals' cash holding, best fits the observed shares of cash payments with notably less demanding information on individual payment patterns. The $\mathrm{CH}$ model can then be considered a more efficient and less complex representation of the way a set of individuals pays.

The remainder of the paper is structured as follows. In section 2 , we present the three models. In section 3, we describe the data, and in section 4 we perform simulations and comment on the results. Finally, section 5 concludes.

\section{Payment Choice Models: A Comparison}

The objective of this part is twofold. First, it provides an indicator that measures how well each model replicates the observed cash payments in the economy. Second, it proposes three models of payment choice that can be used to predict the observed shares of cash payments in an economy.

\subsection{Measuring the Gap between the Observed and Theoretical Shares of Cash Payments}

We define an indicator $\mathbb{G}\left(\mathbb{S}^{o b s}, \mathbb{S}^{t h}\right)$ that measures the gap between the observed shares of cash payments, $\mathbb{S}^{o b s}$, and the shares predicted 
by the model, $\mathbb{S}^{t h}$, that we call "theoretical shares." This indicator is written as follows:

$$
\mathbb{G}\left(\mathbb{S}^{o b s}, \mathbb{S}^{t h}\right)=\sum_{p \in[0, \infty[} \frac{n(p)}{N} \cdot\left|\mathbb{S}^{o b s}(p)-\mathbb{S}^{t h}(p)\right|,
$$

with $\frac{n(p)}{N}$ the frequency of purchases of size $p, n(p)$ the number of purchases worth $p$ in the distribution, and $N=\sum_{p} n(p)$ the total number of purchases in the observations.

This indicator is quite natural since it assigns a higher weight for transaction values that appear more frequently in the distribution. As an illustration, if one predicts that the individual will pay in cash 95 percent of the purchases between 3 and 6 euros whereas the actual observed percentage is 96 percent, the error is more important than predicting that 1 percent of the purchases between 156 and 159 euros will be paid for in cash whereas the actual observed percentage is 0 percent. Indeed, almost $1 / 8$ of all the purchases are between 3 and 6 euros whereas about 1/3000 of the purchases are between 156 and 159 euros. This indicator is particularly well adapted for central banks that need to precisely adjust the stock of banknotes in response to a change in the demand for cash in the economy.

\subsection{Three Models of Payment Choice}

In this section, we respectively present three models of payment choice.

\subsubsection{Transaction Size (TS) Models}

The literature on transaction size models goes back to the transaction demand for money à la Baumol (1952) and Tobin (1956). In these studies, a cost-minimizing consumer has to decide the optimal stock of cash to be held for transaction purposes given the cost of a withdrawal (a fixed fee per withdrawal) and the interest earnings foregone on money holding. Extending this approach to several payment instruments, Whitesell $(1989,1992)$ explicitly assumes that the consumer's problem during a purchase merely consists in choosing a payment instrument which minimizes the holding and transaction costs. In Whitesell (1989), for instance, an individual has the possibility to pay in cash or with an alternative payment instrument. 
Using an alternative payment instrument imposes two costs: a fixed cost per transaction (such as the value of time, etc.) and a variable cost that depends on the size of the transaction. These two costs are both avoided by consumers if they decide to pay with cash. As a result, the problem of consumers is to decide which transactions to make with cash and the amount of cash to hold. Whitesell shows that there exists a threshold below which it is optimal to pay in cash.

Below, we define two TS models of payment choice that derive from the Whitesell approach. The first one is a direct application of the Whitesell model that we call the "naive TS model." The second is a sophistication of the first one, the "probabilistic TS model."

Naive TS Model. In the first model, a representative agent pays in cash when the size of a transaction is smaller than a threshold $l^{(1)}$ and pays with an alternative payment instrument otherwise. Formally, if $\mathbb{S}^{(1)}(p)$ denotes the theoretical share $\mathbb{S}$ of paying with cash a purchase of size $p$ with the naive model $\left({ }^{(1)}\right)$, then

$$
\mathbb{S}^{(1)}(p)=\left\{\begin{array}{l}
1 \text { if } p \leq l^{(1)} \\
0 \text { if } p>l^{(1)}
\end{array}\right.
$$

The threshold $l^{(1)}$ is selected such that the distance $\mathbb{G}\left(\mathbb{S}^{\text {obs }}, \mathbb{S}^{t h}\right)$ is minimal. Let us give a sequence as an example for the naive TS model with $l=25 . l=25$ means that the individual pays in cash if and only if the price is smaller than 25 euros. Assume that, first, the agent faces a buying decision for a good worth 75 euros. Since this good is more expensive than $l=25$ euros, it is paid for with the alternative payment instrument. Assume that, in a second period, the agent faces a buying decision for a good worth 30 euros. Since this good is more expensive than $l=25$ euros, it is then paid for with the alternative payment instrument. Assume that, in a third period, the agent faces a buying decision for a good worth 21 euros. Since this good is less expensive than $l=25$ euros, it is paid for in cash by the agent. If we were stopping here, we would have $\mathbb{S}_{25}^{(1)}(21)=1, \mathbb{S}_{25}^{(1)}(30)=0$, and $\mathbb{S}_{25}^{(1)}(75)=0$.

Probabilistic TS Model. This naive version of the Whitesell approach is extremely simple and can be refined by considering a representative agent drawing by chance a threshold in a distribution 
instead of being constrained to a fixed one. We explain below how the distribution of the thresholds is constructed.

Consider a population composed of $I$ agents. Let $\mathbb{T}_{i}=\left\{p_{1}^{j}, p_{2}^{j}, \ldots\right\}$ denote the set of transactions made by the agent $i$ where $j \in\{c, a\}$ ( $c$ stands for cash and $a$ for alternative payment instruments). We determine the threshold that minimizes the number of "deviations" regarding the transaction size. The number of deviations $m$ when applying the threshold $l$ to the agent $i$ is measured as follows:

$$
m_{i}(l)=\operatorname{card}\left\{p_{k}^{c}: p_{k}^{c} \geq l ; p_{k}^{c} \in \mathbb{T}_{i}\right\}+\operatorname{card}\left\{p_{k}^{a}: p_{k}^{a} \leq l ; p_{k}^{a} \in \mathbb{T}_{i}\right\},
$$

with card referring to the cardinal of a subset. The two terms on the right-hand side deal with the two types of deviations related to the TS model that can be observed. The first one is the number of cash transactions that are above the threshold $l$ and the second term is the number of transactions made with the alternative payment instrument that are below the threshold $l$. Let $\mathbb{L}_{i}$ denote the set of thresholds minimizing the number of deviations for the agent $i:^{3}$

$$
\mathbb{L}_{i}=\operatorname{argmin}_{\left[\min \mathbb{T}_{i}, \max \mathbb{T}_{i}\right]}\left(m_{i}(l)\right) .
$$

We denote $l_{i}=\min \left(\mathbb{L}_{i}\right)$ and $\overline{l_{i}}=\max \left(\mathbb{L}_{i}\right)$. Thus, we build up two distributions of thresholds $\underline{\mathbb{L}}$ and $\overline{\mathbb{L}}$ by aggregating the agents' thresholds $l_{i}$ and $\bar{l}_{i}$. The weight of a threshold $\bar{l}$ in the distribution $\overline{\mathbb{L}}$ is defined as follows:

$$
\mathbb{P}(l=\bar{l})=\frac{\sum_{i ; \overline{l_{i}}=\bar{l}} n_{i}}{N},
$$

with $n_{i}$ the number of transactions of the individual $i$ and $N$ the total number of transactions. ${ }^{4}$

The probabilistic TS models "min" and "max" consists in randomly drawing a threshold from the distribution of thresholds $\underline{\mathbb{L}}$ and $\overline{\mathbb{L}}$, respectively. Then, the share of a worth $p$ transaction to be paid

\footnotetext{
${ }^{3}$ To avoid problems dealing with infinity or zero-value thresholds, we will consider the set $\left[\min \mathbb{T}_{i}, \max \mathbb{T}_{i}\right]$ as the interval of acceptable thresholds for individual $i$.

${ }^{4}$ The same definition applies for the distribution $\underline{\mathbb{L}}$.
} 
in cash is the probability of drawing a threshold above the amount $p$. Formally, in the case of $\overline{\mathbb{L}}$,

$$
\overline{\mathbb{S}}^{(2)}(p)=\mathbb{P}(l \geq p)=\sum_{\bar{l} \geq p ; \bar{l} \in \overline{\mathbb{L}}} \mathbb{P}(l=\bar{l}) .
$$

Computing this decision rule gives the share of the probabilistic TS model "max" $\overline{\mathbb{S}}^{(2)}(p)$ for each good worth $p$ euros to be paid for in cash. $\mathbb{S}^{(2)}(p)$ is calculated in the same way.

Let us give another sequence as an example for the probabilistic TS model with $\bar{l}$. Assume that in the first period, when the price faced is 75 euros, the agent draws by chance a threshold $l=80$. Then, the agent pays in cash since $l \geq 75$. Assume that in the second period, when the price faced is 30 euros, the agent draws by chance a threshold $l=20$. The agent pays with the alternative payment instrument since $l<20$. Assume that in the third period, when the price faced is 21 euros, the agent draws by chance a threshold $l=20$. The agent pays with the alternative payment instrument since $l<21$. If we were stopping here, we would have $\overline{\mathbb{S}}^{(2)}(21)=0$, $\overline{\mathbb{S}}^{(2)}(30)=0$, and $\overline{\mathbb{S}}^{(2)}(75)=1$.

\subsection{Cash Holding ( $\mathrm{CH})$ Model}

Let us now describe the final model, called the $\mathrm{CH}$ model. Unlike TS models, the $\mathrm{CH}$ model does not rely on the transaction size but rather on the individual's cash holding.

In line with the "bottom inventory" assumption of Boeschoten (1992, p. 43), we consider a threshold $t$ that corresponds to the lowest amount of cash held by an agent. We adopt the following sequence of actions for a period. At the beginning, an agent holding an initial amount of cash withdraws an amount $w$ of cash selected randomly in the observed distribution of withdrawals $\mathbb{W}$ until his detention $d$ becomes higher than or equal to $t$. Next he faces a transaction of size $p$ drawn randomly in the observed distribution of transactions denoted $\mathbb{T}$. The agent pays in cash if $p \leq d$ and with an alternative payment instrument otherwise. In the first case, the new agent cash holding becomes $d^{\prime}=d-p$ euros and in the second case $d^{\prime}=d$ euros. Then a new period starts. 
Let $\mathbb{S}^{(3)}(p)$ denote the theoretical share of cash payments when people pay following the $\mathrm{CH}$ model. By definition, $\mathbb{S}^{(3)}(p)=1$ when $p \leq d$ because the individual's cash holding is always higher than $d$. Otherwise, the purchase can be paid for in cash or with an alternative payment instrument, depending on the agents' holding of cash $d$ which itself results from the history of purchases and withdrawals. ${ }^{5}$

Let us give another sequence of prices as an example for the $\mathrm{CH}$ model with $d=5$, which means that the individual goes to withdraw cash when the amount of cash he holds is below 5 euros. Moreover, consider an agent holding 100 euros in cash at the beginning of the period. When the representative agent is facing a good worth 75 euros, he pays for it in cash. Then, he has 25 euros remaining in cash. Since the threshold $d$ is not reached, the individual does not withdraw any cash. When facing the second good, worth 30 euros, since the agent cannot pay with cash, he pays with the alternative payment instrument. He still has 25 euros in cash and, for the same reasons as above, does not withdraw any cash. When facing the third purchase opportunity, worth 21 euros, since the agent can pay in cash, he does so. He now has 4 euros in cash remaining and since his cash holding is below $d$, he goes to an ATM or to his bank to refill. If he withdraws, say, 20 euros, the model goes on with the agent having 24 euros in cash.

\section{Cash Payments in the French Economy}

This section aims at presenting the data we use to replicate the observed shares of cash payments in 2005 and 2011.

We conducted two surveys in 2005 and 2011 on two representative samples of 1,447 and 1,106 French individuals of eighteen years and older. ${ }^{6}$ The surveys are structured and constructed in the same way and have two parts. The first is a questionnaire designed to collect, during face-to-face interviews, payment methods, individuals' finances, socioeconomic characteristics (such as gender, age, income, and profession), and individual's cash acquisition. Survey participants were more precisely asked about their weekly cash withdrawals (average number of withdrawals and average amount of the

\footnotetext{
${ }^{5}$ An axiomatization of the $\mathrm{CH}$ model is provided in Bounie and Houy (2007).

${ }^{6}$ Respondents had never participated in any survey before.
} 
withdrawal). ${ }^{7}$ We can therefore use this information to characterize the statistical distribution of the amount of withdrawals in the French economy denoted previously by $\mathbb{W}$ in the $\mathrm{CH}$ model.

The second survey is an eight-day shopping diary in which each respondent reports information on daily purchases. $^{8} \mathrm{~A}$ purchase is characterized by several pieces of information such as the amount to be paid (size of transaction) and the type of payment instrument used (cash, payment card, etc.). Out of 1,447 and 1,106 respondents, 1,386 and 1,047 individuals have completed the diaries. ${ }^{9}$ As a result, we are able to calculate for those individuals the transactions paid with each payment instrument and then the distribution of transactions $\mathbb{T}$ in the French economy.

Overall, the shopping diaries in 2005 and 2011 include 16,174 and 10,471 transactions, respectively. ${ }^{10}$ A description of the distributions of purchases paid for in cash or with alternative payment instruments is plotted in figure $1 .{ }^{11}$ As also pointed out in other international studies (Boeschoten 1992; Mooslechner, Stix, and Wagner 2006; Klee 2008), the larger part of transactions are small-value purchases. In 2011 for instance, 21.7 percent of all the transactions are lower than 2 euros (23 percent in 2005), 46.1 percent lower than 10 euros (50.2 percent in 2005), and 62 percent lower than 20 euros (66.5 percent in 2005).

Continuing the data exploration, 64 percent of the purchases are paid for in cash in 2005, compared with 58 percent in 2011, a drop of 6 percentage points. This finding confirms a decrease of cash in payments mainly to the benefit of the payment card. The average value of a cash transaction amounts to 10.7 euros in 2005 and 9.8 euros in 2011 (compared with 67 and 76 euros for the average values

\footnotetext{
${ }^{7}$ The questions are "On average, how many times per week do you withdraw cash from ATMs?" and "On average, how much cash do you withdraw from ATMs?"

${ }^{8}$ Professional expenses and bill payments were excluded from diaries.

${ }^{9}$ The method of the diary is common to several international studies such as Boeschoten (1992), Mooslechner, Stix, and Wagner (2006), and von Kalckreuth, Schmidt, and Stix (2009).

${ }^{10}$ Transaction prices above 1,000 euros have been dropped from the samples, i.e., twenty-one transactions in 2005 and fourteen in 2011. These transactions prices are considered as outliers.

${ }^{11}$ In all the figures presented, data are summed for purchase classes of 3 euros thickness.
} 
Figure 1. Distribution of the Frequency of Transactions in 2005 and 2011 as a Function of the Transaction Size (in logarithm)

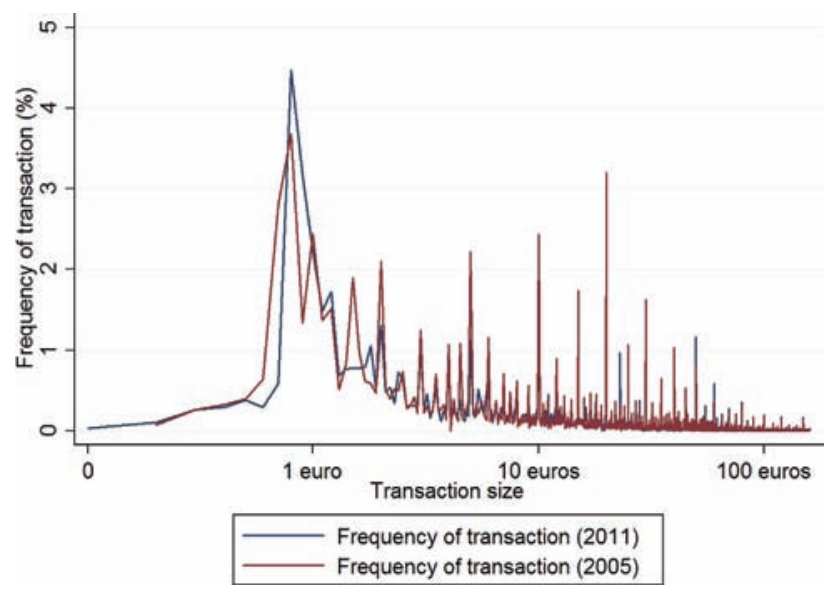

of transactions paid with alternative payment instruments, respectively). Cash transactions in 2011 are then more concentrated on small-value transactions, as confirmed in figure 2 . The cash market shares for transactions of under 5 euros is about 90 percent in 2005 and 2011. However, the cash market shares quickly decrease: when the transaction size is around 16 euros, cash and alternative payment instruments market shares are equal. Beyond those transaction sizes, debit card and check payments are dominant. This result is fairly in line with Mooslechner, Stix, and Wagner (2006), who find that cash is mostly used for small-value payments.

To follow the description, we can describe the payments at the level of individuals. The average number of transactions made by each individual is 11.6 in 2005 and 10 in 2011. These statistics are close to those of Mooslechner, Stix, and Wagner (2006), who report that Austrian people carry out on average twelve payments per person per week. We note, however, that the share of cash payments (in total transaction volume) in France is lower than that in Austria (86 percent) and Germany (79 percent) (von Kalckreuth, Schmidt, and Stix 2009) and, therefore, that the shares of other payment instruments are slightly higher. The drop in the number of transactions (from 11.6 to 10) goes hand in hand with a decrease in the number 
Figure 2. Observed Shares of Cash Payments in 2005 and 2011 (Below Dashed and Solid Lines) as a Function of the Transaction Size

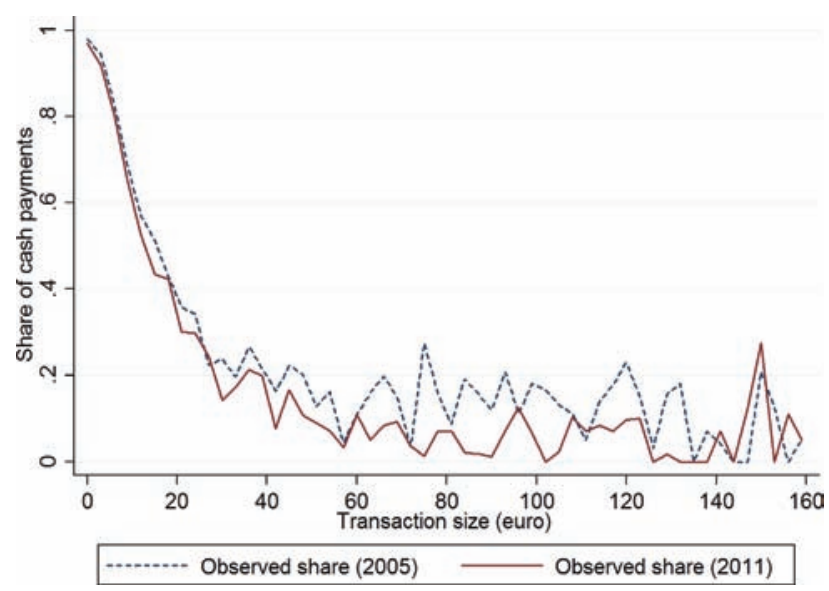

of cash transactions per individual that goes from 7.5 in 2005 to 5.8 in 2011 . In 2005, $5.5 \%$ (seventy-seven people) of the individuals do not make a cash payment over the week, while this figure reaches 8.6 percent in 2011.

Since we know the distribution of the transaction sizes by payment instrument and for each individual, we are then able to check if the naive TS model is good at replicating the payment patterns of each individual in the sample. In doing the above, it is important to note that out of 1,047 individuals in 2011 (1,386 in 2005), 212 (281 in 2005) have settled the totality of their purchases using only one payment instrument (either cash or an alternative instrument). As a result, if we only focus on these people who use at least two payment instruments (i.e., 835 in 2011 and 1,105 people in 2005), then we find that 45.5 percent (43.4 percent in 2005) of the individuals in the sample do not satisfy the naive TS model. In other words, for these individuals we do not observe strict domains of transactions for the payment instruments but rather overlapping transactions domains.

Applying literally the test of equation (2) is, however, a little bit too restrictive. As a consequence, we could test whether the 
inequality holds on average for each individual to allow for some measurement error. For instance, we could calculate the mean and the median of the transaction sizes paid with cash and alternative payments in order to check if the average (median) cash transaction paid for in cash is lower than or equal to the average (median) alternative transaction for each individual (i.e., $p_{\text {cash }}^{\text {mean }} \leq p_{\text {alternative }}^{\text {mean }}$ and $\left.p_{\text {cash }}^{\text {median }} \leq p_{\text {alternative }}^{\text {median }}\right)$. Since the average cash transaction size is six times lower than that made with an alternative instrument, we expect that many more individuals will satisfy this naive extended TS model. This is what we precisely obtain: excluding the people who use only one payment instrument in transactions, we find that 95.5 percent (97.6 percent in 2005) of the people satisfy the test when the averages of the cash and alternative transactions are concerned and 95.6 percent (97.8 percent) when the medians of the cash and alternative transactions are considered.

We conclude these preliminary descriptive statistics by giving an overview of the individuals' cash withdrawals. An individual makes on average 1.1 and 0.9 withdrawals in 2005 and 2011 for an average value of 68.8 euros and 73.3 euros, respectively. ${ }^{12}$ We refer to $\mathbb{W}$ in the following to describe the distribution of the amounts of cash withdrawals in the French economy.

\section{Simulations and Results}

This section aims at measuring how well each of the payment choice models defined in section 2 replicates the observed shares of cash payments illustrated in section 3 . To do that, we describe first the method of simulations and then comment on the results.

\subsection{Method of the Simulations}

To begin with the naive TS model, a representative agent pays in cash when the purchase he faces is below a given threshold; otherwise, he uses an alternative payment instrument. The threshold is selected so as to minimize the indicator (cf. section 2.1) between the

\footnotetext{
${ }^{12}$ The value of transactions for the year 2005 accounts for inflation (€1 (2005) = $€ 1.06$ (2011)).
} 
observed and theoretical shares of cash payments for each transaction size. To simulate this model, the only information we need is the observed share of cash payments for each transaction size in the French economy.

Turning to the probabilistic TS model, we first calculate the minimum and maximum thresholds $\left(\underline{l_{i}}\right.$ and $\left.\bar{l}_{i}\right)$ for each individual $i$ based on the rule described in section 2 and then aggregate them to build up the distributions of thresholds $\mathbb{L}$ and $\overline{\mathbb{L}}$ for all the individuals. Next, we compute the theoretical shares of cash payments for each purchase of the distribution $\mathbb{T}$ using equation (3). It is worth noting that this model requires more data than the naive TS model since we need to calculate the thresholds $\bar{l}_{i}$ and $\underline{l}_{i}$ for each individual $i$. In our study, since we have more than 1,000 individuals in each respective survey, we need to have all the information about the payment patterns of each of them.

For the $\mathrm{CH}$ model, the simulation requires the distribution of transactions in the economy, $\mathbb{T}$, and the distribution of cash withdrawals, $\mathbb{W}$. Concretely, the algorithm consists in simulating a very high number of successive periods (one million), each one being divided into two stages. In the first stage, the representative agent checks his new cash holding and withdraws cash in the distribution of cash withdrawals $\mathbb{W}$ if his cash holding is below a threshold $t$. In the second stage, he faces a purchase of size $p$ drawn randomly from the distribution of transactions $\mathbb{T}$. He pays for this purchase with cash when his cash holding is sufficient and with an alternative payment instrument otherwise.

\subsection{Results}

Let us now comment on the results of the simulations. To simplify the presentation, we decided to only report in the sequel the simulation results from the year 2011 since the results are very similar to 2005 . The simulation results of the year 2005 are provided in the appendix.

For the naive TS model, the indicator $\mathbb{G}\left(\mathbb{S}^{o b s}, \mathbb{S}^{(1)}\right)$ is minimum for $l^{(1)}=15.6$. In other words, we find that the theoretical shares of cash payments obtained with the naive TS model deviate by 17.5 percent on average from the observed ones. This gap is the minimum that can be reached with this model. Figure 3 shows $\mathbb{S}^{o b s}$ and 


\section{Figure 3. Observed $S^{o b s}$ and Theoretical $S_{15.6}^{(1)}$ Shares of Cash Payments as a Function of the Transaction Size}

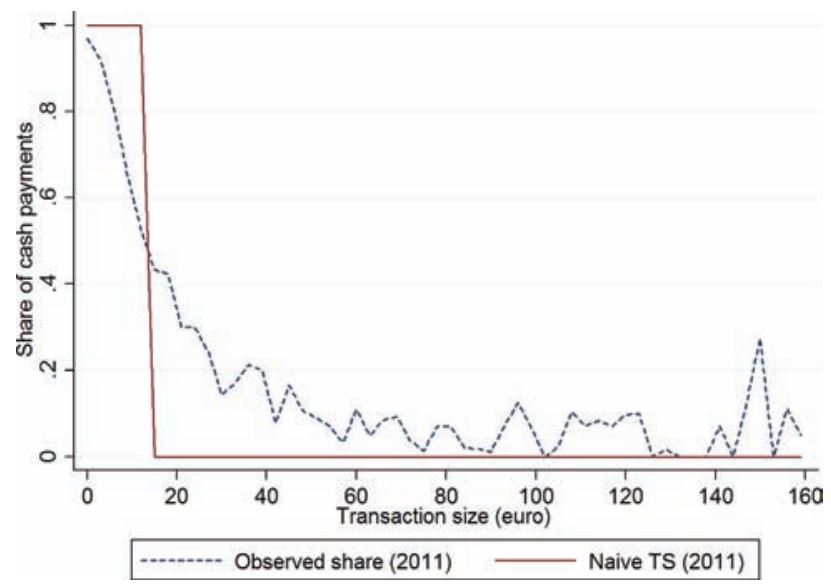

$\mathbb{S}_{15.6}^{(1)}(p)$ for values of $p$ between 0 and 160 euros. To give an intuition of this result, let us describe what happens when the threshold is greater or lower than 15.6 euros. To begin with, when the threshold is below 15.6, the percentage of deviations (measured by the indicator) increases because the naive TS model predicts that more transactions are paid with an alternative payment instrument, whereas in reality more transactions are paid for in cash (figure 3 ). On the contrary, beyond 15.6 euros, the difference between the observed and theoretical probabilities increases because the naive TS model predicts that more transactions are paid for in cash whereas observed transactions are more often paid with other payment instruments.

Not surprisingly, the naive TS model does not replicate very well the observed cash payments in the French economy.

Let us now consider the probabilistic TS model. $\overline{\mathbb{S}}^{(2)}(p)$ and $\underline{\mathbb{S}}^{(2)}(p)$, the theoretical shares of cash payments obtained with the probabilistic TS models, are shown in figure 4 together with $\mathbb{S}^{o b s}$. Obviously, $\overline{\mathbb{S}}^{(2)}(p)$ is above $\underline{\mathbb{S}}^{(2)}(p)$ for each $p$. Indeed, by definition, $\overline{l_{i}} \geq \underline{l_{i}}$ for each individual $i$. Hence, more purchases are made in cash when using $\bar{l}$ than when using $\underline{l}$.

In this case, we find that $\mathbb{G}\left(\mathbb{S}^{o b s}, \overline{\mathbb{S}}^{(2)}\right)=10.4$ percent and $\mathbb{G}\left(\mathbb{S}^{o b s}, \mathbb{S}^{(2)}\right)=9.1$ percent. Hence, the probabilistic TS model is 
Figure 4. Observed $S^{o b s}$ and Theoretical $\bar{S}^{(2)}(p), \underline{S}^{(2)}(p)$ Shares of Cash Payments as a Function of the Transaction Size

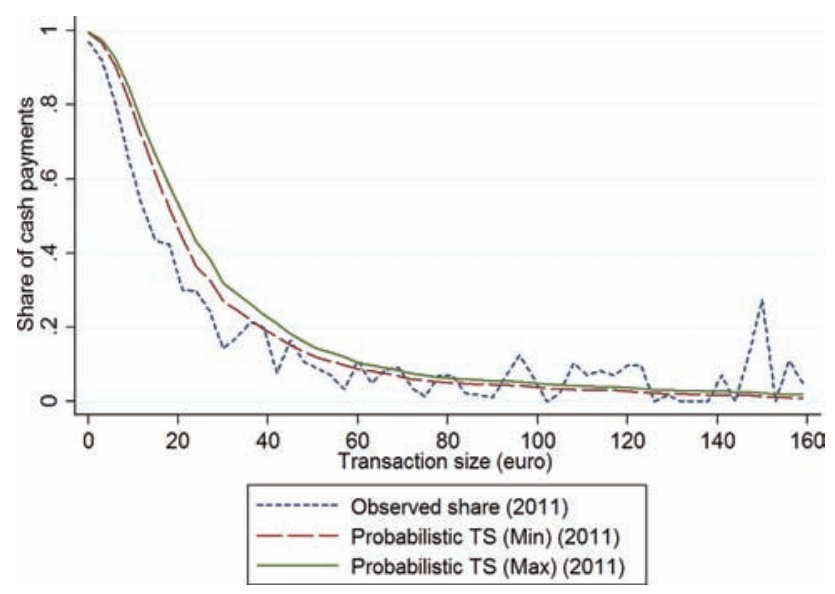

around two times better than the naive TS model at replicating the observed shares of cash payments in the French economy.

We finally present and comment on the results for the $\mathrm{CH}$ model.

The indicator $\mathbb{G}\left(\mathbb{S}^{o b s}, \mathbb{S}^{(3)}\right)$ is calculated for different values of the threshold $t$. According to the $\mathrm{CH}$ model, for small values of $t$, the agent goes rarely to the ATM and then carries little cash. Then, the representative agent often pays with an alternative payment instrument. On the contrary, for great values of $t$, the agent often withdraws cash. Then, he often pays with cash. In between those values, the representative agent's behavior gets closer to what is observed. We find more precisely that the $\mathrm{CH}$ model fits the data with an average deviation of only 8.4 percent, compared with the observed data when the threshold is set at $t=4.1$. This result suggests that the $\mathrm{CH}$ model performs better than the naive and the probabilistic TS models. The theoretical and observed probabilities to pay in cash as a function of the transaction price are depicted in figure 5 . We can see that the $\mathrm{CH}$ model behaves particularly well for small-value purchases (0-20 euros) but is not as good for largevalue purchases. However, since most of the transactions take place for small-value purchases, as can be seen in figure 1 and as was 
Figure 5. Observed $S^{o b s}$ and Theoretical $S_{4.1}^{(3)}$ Shares of Cash Payments as a Function of the Transaction Size

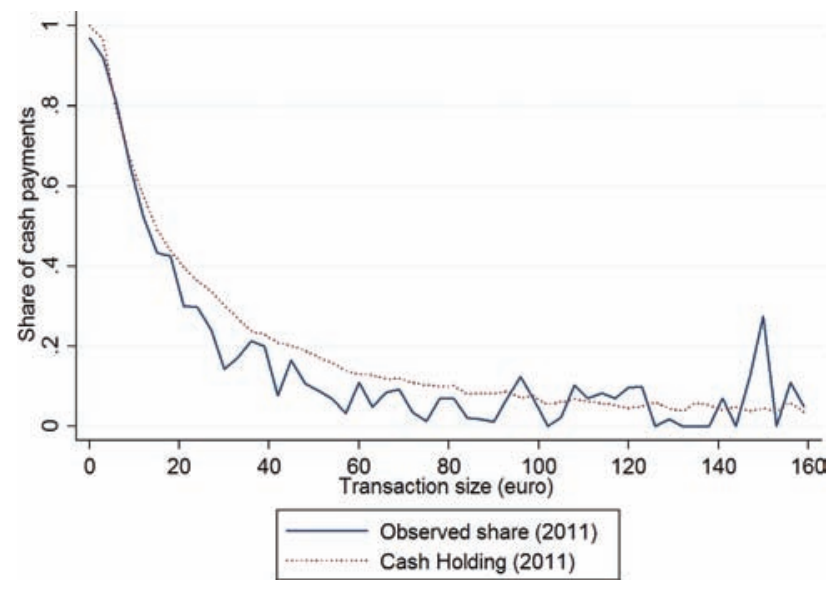

commented on earlier, the predictions of the $\mathrm{CH}$ model show a very good fit with the observed data.

To end this section, we sum up our results in table 1 and give an overview of all the graphical results in figure 6 .

\section{Concluding Discussion}

This study aims at better understanding the way the public pays cash by comparing three models in their ability to replicate the observed shares of cash payments in the French economy for the years 2005 and 2011. The first model assumes the existence of a unique transaction size or threshold for all the agents that determines a frontier between cash and non-cash payments. This model poorly replicates the observed shares of cash payments. The second model is a refinement of the first one and allows each agent to have a specific threshold. Unlike the first model, we use a probabilistic distribution of thresholds built up from the payment behaviors of individuals. This probabilistic model performs better than the first one. The third and last model tests a totally different assumption based on individual's cash holding. The agent pays cash whenever he has enough cash and with another payment instrument otherwise; if 
Table 1. Summing Up of the Results

\begin{tabular}{|l|c|c|}
\hline Models & $\mathbb{G}\left(\mathbb{S}^{\text {obs }}, \mathbb{S}^{\text {th }}\right)$ & Threshold \\
\hline Naive TS Model $\left(\mathbb{S}^{(1)}\right)$ & $17.5 \%$ & $€ 15.6$ \\
Probabilistic TS Model $\left(\overline{\mathbb{S}}^{(2)}\right)$ & $2^{*} 10.4 \%$ & $\min \bar{l}=€ 0.3 ; \max \bar{l}=€ 980$ \\
$\operatorname{mean}(\bar{l})=€ 31.1$ \\
Probabilistic TS Model $\left(\underline{\mathbb{S}}^{(2)}\right)$ & $2^{*} 9.1 \%$ & $\begin{array}{c}\min =€ 0.3 ; \max \underline{l}=€ 640 \\
\operatorname{mean}(\underline{l}) € 37.1\end{array}$ \\
CH Model $\left(\mathbb{S}^{(3)}\right)$ & $8.4 \%$ & $€ 4.1$ \\
\hline
\end{tabular}

Figure 6. Observed $S^{o b s}$ and Theoretical $\bar{S}^{(2)}(p), \underline{S}^{(2)}(p)$ and $S_{4.1}^{(3)}$ Shares of Cash Payments as a Function of the Transaction Size

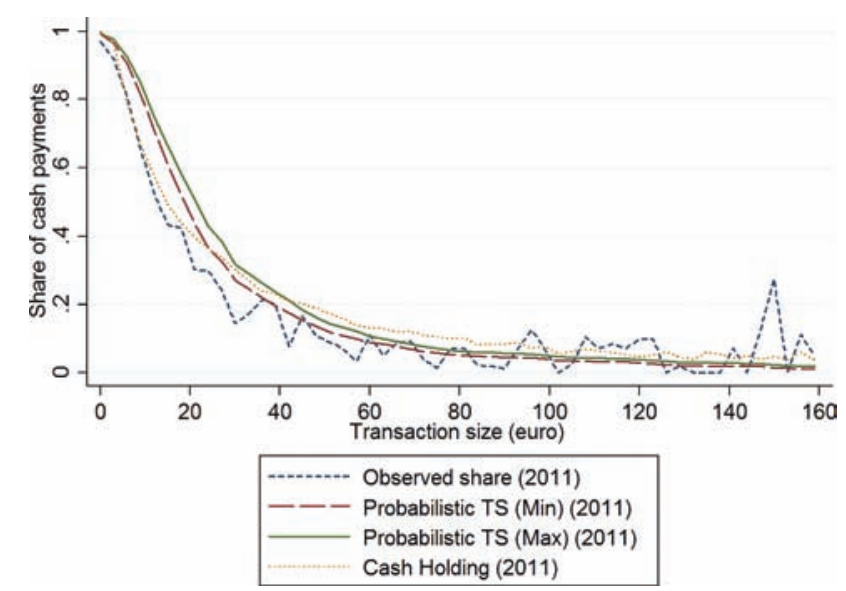

his cash balance is lower than a threshold, he withdraws an amount of cash from the observed distribution of cash withdrawal amounts. The simulations show that this model better fits the observed shares of cash payments than the two previous models. We can therefore conclude that the payment behavior of the public is more driven by a cash holding rule than by a transaction size rule.

Besides its capacity to explain the payment behavior of people, this research can be used to better predict the demand for cash in 
an economy. Various payment innovations have indeed been conceived in recent years to replace cash payments on specific transaction domains. For instance, a contactless payment card has recently been launched in France by the main commercial banks to compete with cash, especially for transactions below 20 euros. ${ }^{13}$ In the United Kindom and the United States, the threshold has been set up to $£ 20$ and to US $\$ 25$, respectively. ${ }^{14}$ According to Whitesell (1989), the new competing payment instruments should lead people to hold lower cash balances. Now, using the $\mathrm{CH}$ model, a lower withdrawal threshold will result in lower cash balances. Therefore, the model can be used by the central bank to estimate how the adoption of new payment technologies would affect the use of cash for each size of transaction and, in turn, better adapt the issuing of coins and notes.

To conclude, it is important to emphasize that the cash holding model is by far less complex to implement than the probabilistic model since it relies on a very minimal information basis. Indeed, three pieces of information are needed to simulate the $\mathrm{CH}$ model: the distributions of transaction and cash withdrawal amounts and the threshold under which the representative agent goes back to withdraw cash. On the contrary, the probabilistic model requires the computation of a threshold (transaction size) for each individual which is an obvious informational and computational limit. However, to test the robustness of the $\mathrm{CH}$ model, it would be interesting in a future work to perform simulations on other payment data sets to check if the results obtained for the specific case of France are also valid for other countries.

\section{Appendix}

In this appendix, we provide the results of the simulations for the year 2005 that we summarize in table 2. As also illustrated in figure 7 , the results are very close to those obtained for the year 2011.

\footnotetext{
${ }^{13}$ No signature or PIN entry is typically required for small-value purchases.

${ }^{14}$ At the end of January 2012, 23.3 million contactless cards had been issued in the United Kingdom (www.theukcardsassociation.org.uk).
} 
Table 2. Summing Up of the Results for the Year 2005

\begin{tabular}{|l|c|c|}
\hline Models & $\mathbb{G}\left(\mathbb{S}^{\text {obs }}, \mathbb{S}^{\text {th }}\right)$ & Threshold \\
\hline Naive TS Model $\left(\mathbb{S}^{(1)}\right)$ & $17.0 \%$ & $€ 15.6$ \\
Probabilistic TS Model $\left(\overline{\mathbb{S}}^{(2)}\right)$ & $2^{*} 9.0 \%$ & $\min \bar{l}=€ 0.7 ; \max \bar{l}=€ 950$ \\
Probabilistic TS Model $\left(\underline{\mathbb{S}}^{(2)}\right)$ & $2^{*} 7.7 \%$ & $\operatorname{mean}(\bar{l})=€ 37.6$ \\
$\min \underline{l}=€ 0.7 ; \max \underline{l}=€ 950$ \\
$\mathrm{CH}$ Model $\left(\mathbb{S}^{(3)}\right)$ & $7.3 \%$ & $\operatorname{mean}(\underline{l}) € 40.3$ \\
\hline
\end{tabular}

Figure 7. Observed $S^{\text {obs }}$ and Theoretical $\bar{S}^{(2)}, \underline{S}^{(2)}$ and $S^{(3)}$ Shares of Cash Payments as a Function of the Transaction Size in 2005

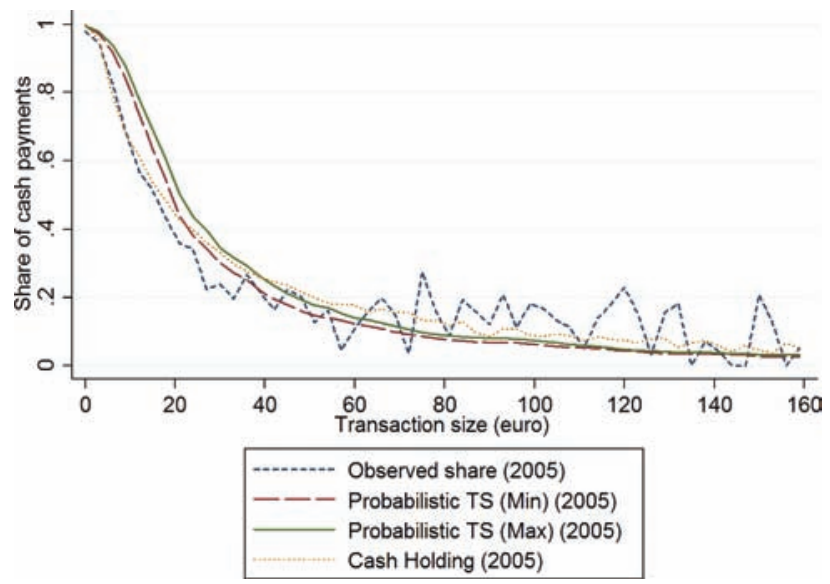

We find more precisely that the $\mathrm{CH}$ model fits the data with an average deviation lower than 7.3 percent when the threshold is set at $t=4$.1. This result also suggests that the $\mathrm{CH}$ model performs better than the naive and the probabilistic TS models. Indeed, for the naive TS model, the indicator $\mathbb{G}\left(\mathbb{S}^{o b s}, \mathbb{S}^{(1)}\right)$ is minimum, 17 percent, for $l^{(1)}=15.6$. Likewise, we find that $\mathbb{G}\left(\mathbb{S}^{o b s}, \overline{\mathbb{S}}^{(2)}\right)=9$ percent and $\mathbb{G}\left(\mathbb{S}^{o b s}, \mathbb{S}^{(2)}\right)=7.7$ percent. Hence, the probabilistic TS models are better than the naive TS model at replicating the observed shares of cash payments in the French economy but are also worse than the CH model. 


\section{References}

Alvarez, F. E., and F. Lippi. 2009. "Financial Innovation and the Transactions Demand for Cash." Econometrica 77 (2): 363-402. Baumol, W. J. 1952. "The Transaction Demand for Cash-An Inventory Theoretic Approach." Quarterly Journal of Economics 66 (4): 545-56.

Boeschoten, W. C. 1992. Currency Use and Payment Patterns. Kluwer Academic Publishers.

Bounie, D., and A. Franois. 2006. "Cash, Check or Bank Card? The Effects of Transaction Characteristics on the Use of Payment Instruments." Telecom Paris Economics and Social Sciences Working Paper No. 06/05/ESS.

- 2011. "The Economics of Bill Payments: An Empirical Analysis." Applied Economics Letters 18 (10): 961-66.

Bounie, D., and N. Houy. 2007. "A Model of Demand for Cash and Deposits." Telecom Paris Economics and Social Sciences Working Paper No. 07/13/ESS.

Carow, K., and M. E. Staten. 1999. "Debit, Credit, or Cash: Survey Evidence on Gasoline Purchases." Journal of Economics and Business 51 (5): 409-21.

Folkertsma, C. K., and G. E. Hebbink. 1998. "Cash Management and the Choice of Payment Media: A Critical Survey of the Theory." Econometric Research and Special Studies Department, Netherlands Central Bank, Research Memorandum WO and Enr 532.

Hayashi, F., and E. Klee. 2003. "Technology Adoption and Consumer Payments: Evidence from Survey Data." Review of Network Economics 2 (2): 175-90.

Klee, E. 2008. "How People Pay: Evidence from Grocery Store Data." Journal of Monetary Economics 55 (3): 526-41.

Lippi, F., and A. Secchi. 2009. "Technological Change and the Household's Demand for Currency." Journal of Monetary Economics 56 (2): 222-30.

Mooslechner, P., H. Stix, and K. Wagner. 2006. "How Are Payments Made in Austria? Results of a Survey on the Structure of Austrian Households' Use of Payment Means in the Context of Monetary Policy Analysis." Monetary Policy 85 the Economy 2: $111-34$. 
Mot, E. S., and J. Cramer. 1992. "Mode of Payment in Household Expenditures." De Economist 140 (4): 488-500.

Santomero, A. 1974. "A Model of the Demand for Money by Households." Journal of Finance 29 (1): 89-102.

1979. "The Role of Transaction Costs and Rates of Return on the Demand Deposit Decision." Journal of Monetary Economics 5 (3): 343-64.

Santomero, A., and J. J. Seater. 1996. "Alternative Monies and the Demand for Media of Exchange." Journal of Money, Credit and Banking 28 (4): 942-60.

Shy, O., and J. Tarkka. 2002. "The Market for Electronic Cash Cards." Journal of Money, Credit and Banking 34 (2): 299-314. Tobin, J. 1956. "The Interest Elasticity of Transaction Demand for Cash." Review of Economics and Statistics 38 (3): 241-47.

von Kalckreuth, U., T. Schmidt, and H. Stix. 2009. "Choosing and Using Payment Instruments: Evidence from German Microdata." ECB Working Paper No. 1144.

Whitesell, W. C. 1989. "The Demand for Currency versus Debitable Accounts." Journal of Money, Credit and Banking 21 (2): $246-51$.

- 1992. "Deposit Banks and the Market for Payment Media." Journal of Money, Credit and Banking 24 (4): 483-98.

Zinman, J. 2009. "Debit or Credit?" Journal of Banking and Finance 33 (2): 358-66. 